\title{
The role of causal discourse structure in narrative writing
}

\author{
PAUL VAN DEN BROEK, BRIAN LINZIE, CHARLES FLETCHER, and CHAD J. MARSOLEK \\ University of Minnesota, Minneapolis, Minnesota
}

\begin{abstract}
All writers produce text content and ideally connect it together according to discourse conventions. We investigate whether a particularly strong discourse convention, the need for causal coherence in narratives, can predict the kind of text writers will produce. Causality has been found to be a significant discourse factor in reading comprehension and hence can be expected to determine also what writers produce during composition. In Experiment 1, writers composed short continuations at various points throughout a simple narrative, whereas in Experiment 2, writers composed continuations to complete several narratives. The results indicate that causality indeed plays a major role in composition. Writers tend to produce new text in such a way that it is causally connected to the prior text. Furthermore, writers favored causal relations of necessity or of necessity and sufficiency while largely avoiding relations of sufficiency alone, which suggests a general discourse constraint to be maximally informative (e.g., Grice, 1975).
\end{abstract}

All writers must produce ideas (Collins \& Gentner, 1980; Torrance, Thomas, \& Robinson, 1996) and ideally, writers also provide coherence by connecting those ideas in some genre-appropriate way (McCutchen \& Perfetti, 1982). Bereiter and Scardamalia $(1985,1987)$ captured these observations by describing two sets of knowledge on which writers draw during writing: (1) Writers use topic knowledge (including the evolving text) to produce relevant ideas, and (2) writers use discourse knowledge to structure how the ideas are arranged and to determine which topic ideas are relevant (McCutchen, 1986; McCutchen \& Perfetti, 1982).

Topic and discourse knowledge play important, but different, roles in determining which ideas are produced and how they are ultimately connected. For example, if a writer knows more about baseball and less about soccer (varying topic knowledge), the writer has different limits in what he/she is able to say when composing a description of each game. Regardless of topic knowledge, however, the writer's discourse knowledge should cue him/her to attempt to say something in each of several categories for the genre of "game description," such as mentioning "the object of the game," "the rules," "the number of players," and so on (e.g., Bereiter \& Scardamalia, 1982; Kroll,

The research was supported by the Golestan Foundation at the Netherlands Institute for the Advanced Study in the Humanities and Social Sciences, the Minnesota Center for Cognitive Sciences at the University of Minnesota, by the National Institute of Child Health and Human Development (HD-07151), and by the Guy Bond Endowment for Reading and Literacy. Some of these data were presented at the American Educational Research Association meeting in 1989. We thank Susan Chrysler for coding data and Amy Briggs, Ronald Kellogg, and Matt Traxler for helpful comments on an earlier draft. Correspondence should be addressed to P. van den Broek, Department of Educational Psychology, University of Minnesota, 178 Pillsbury Drive SE, Minneapolis, MN 55455 (e-mail: pvdbroek@maroon.tc.umn.edu).
1986). Coe (1987) has referred to conventions for the form of the discourse as heuristics that help writers search for particular kinds of information to produce for text. A very explicit example of discourse conventions exists in the $P u b$ lication Manual of the American Psychological Association (1994), which helps writers by specifying what kinds of ideas are considered relevant for a research report and how they are to be arranged. Thus, available topic information limits specific content, whereas discourse knowledge influences what kinds of topic information are produced and how they are connected. If this view is correct, it should be possible, given a genre with well-known discourse conventions, to make predictions about the kinds of ideas writers will generate while composing and how they will try to connect the ideas together. In this series of studies we investigate the notion that discourse structure determines how writers produce and connect new ideas. We do so in the context of writing short narratives because the structure of such texts is particularly well known.

One source of knowledge about the structure of narrative texts consists of studies of narrative comprehension. These studies have shown that causal relations among story events constitute a major factor in how readers understand narratives, suggesting that they are an important part of narrative discourse structure. Five types of evidence have been gathered. First, statements that have more causal connections to other statements in a narrative are more often recalled than statements with few connections (Goldman \& Varnhagen, 1986; Graesser, 1981; Graesser \& Clark, 1985; Trabasso, Secco, \& van den Broek, 1984; Trabasso \& van den Broek, 1985; van den Broek, 1988; van den Broek, Rohleder, \& Narvaez, 1996). Second, statements with more causal connections are accessed in memory more quickly than statements with fewer connections (O'Brien \& Myers, 1987). Third, the strength of the causal relation between two statements determines 
the degree to which one primes memory retrieval of the other (Keenan, Baillet, \& Brown, 1984; McKoon \& Ratcliff, 1992; Myers, Shinjo, \& Duffy, 1987). Fourth, readers' attention follows the causal connections among events (Fletcher, Hummel, \& Marsolek, 1990). And fifth, readers make forward inferences provided that such inferences serve a causal function, for example, by resolving a break in the narrative's causal coherence or by fulfilling strong causal constraints in the preceding text (Murray, Klin, \& Myers, 1993; see also van den Broek, Risden, \& Husebye-Hartmann, 1995). Given the critical role that causal relations play in the comprehension of narratives, it would seem likely that writers of narratives tend to produce and retain ideas that are causally connected to the preceding text and, further, that they do so throughout a narrative.

Causality is not a unitary concept. Psychologists have adapted two components of the logical notion of causality, necessity and sufficiency, to determine whether or not a causal relation exists between two story events. A particular story event (the antecedent) is said to be necessary for another (the consequent) if, in the circumstances of the story, the consequent would not have occurred if the antecedent had not taken place (van den Broek et al., 1995). In contrast, one story event is considered sufficient for another if, in the circumstances of the story, the first event is likely to be followed by the second (see also Hart \& Honore, 1985; Mackie, 1980). The causal relation between two story events is strongest when it includes both necessity and sufficiency (van den Broek, 1990a). If writers rely on causality for generating and connecting new content, they may rely equally on both components or they may focus more on one causal component than the other. Thus, in the present set of studies we wish to determine (1) whether or not causal relations are important in producing new ideas, and (2) if so, whether writers produce content that is causally antecedent to or consequent to prior text, and (3) whether causal relations between new ideas and previous text are based on causal relations of necessity, sufficiency, or both necessity and sufficiency. In doing so, we focus on the local aspects of text production - that is, on the connections existing within a span of several sentences.

To study how writers produce new ideas and the possible relations between these new ideas and the preceding text, it is important to experimentally control the knowledge upon which writers draw or the focus of their attention (van Dijk \& Kintsch, 1983). Researchers can exert such experimental control by providing writers with partial text. For example, Hiebert, Englert, and Brennan (1983) provided writers with an opening sentence that specified the topic and signaled a particular text structure (such as comparison-contrast) for which the writers were to compose the remainder of the paragraph. Similarily, Kemper (1982) used a "gap-filling" paradigm in which students read short narratives and were told to compose new sentences wherever they felt some events might be missing. And Bereiter and Scardamalia (1982) summa- rized several investigations (e.g., unpublished work with Tetroe, and research by Hildyard \& Hidi, 1980) in which children were given beginning, ending, or both beginning and ending sentences for short narratives, which specified the topic and various text problems the children were to address. In each case, the investigators manipulated the information writers used as input for generating new text - a method similar to that used in investigations of the inferences people generate during reading.

In the following experiments, we took a similar approach and used a "continuation paradigm" to balance experimental control and the generative creativity of writing. We provided sections (narrative stems) of short narratives and asked participants to write continuations to them. We experimentally manipulated the narrative stems to investigate how writers might produce new ideas that are causally connected to prior text. Providing a narrative stem directs each writer's attention as much as possible to the same topic and discourse knowledge. It also reduces variability in participant responses by modeling other discourse features such as sentence length, tone, level of detail, and so on. Across Experiments 1 and 2 we varied the number of continuation prompts and the form of the prompt to ensure the generality of any observed effects of causality.

The main benefit of the continuation paradigm derives from the experimental control it affords. A secondary benefit for our study is the fact that similar methods have been used successfully to expose the role causality plays when readers make forward inferences. The generation of a forward inference, as occurs in reading, is one process writers can use to generate new text ideas (Hayes, 1996). Whereas a reader's forward inference constitutes a prediction about what might happen next, a writer's forward inference constitutes the generation of a possible next content idea.

In summary, our investigation of idea production focuses on the ideas that are produced in response to constraints present in the prior narrative text. It focuses on how writers build onto what they may have already written, rather than on the less constrained idea production one might see in predocument brainstorming. Specifically, we investigate whether writers build onto narratives, as readers do in narrative comprehension, by attending to causal relations among events in a story. Further, we determine what types of causal relations (necessity, sufficiency, or both; antecedent or consequent) writers establish in producing continuations.

\section{EXPERIMENT 1}

Experiment 1 addressed four specific questions. First, do writers produce continuations that are causally related to the last sentence of the prior text? Second, if continuations are causally related to the last sentence of the narrative stem, are they antecedent or consequent to it? Third, if the continuations are causally related, do they constitute relations of necessity, sufficiency, or of both 
necessity and sufficiency? And fourth, are causal relations important for generating continuations throughout a simple narrative?

The various distinctions regarding causal relations among narrative events are perhaps best illustrated through examples. For instance, a writer might generate any of the continuations A-D in response to Events 1 and 2 in the following narrative stem:

Narrative Stem 1) Jimmy got up from the kitchen table and opened the door.

Narrative Stem 2) Jimmy walked through the doorway.

Continuation A) Jimmy was now outside the room.

Continuation B) Jimmy slammed the door behind himself.

Continuation C) Jimmy adjusted the collar on his shirt.

Continuation D) He was fed up waiting.

According to causal principles, Narrative Stem 1 is necessary for 2 in the context of this story; if Jimmy opened the door, then it must have been closed and he would need to open it (it was necessary) before he could walk through the doorway. What are the causal relations to the continuations? The second sentence in the narrative stem (2) is sufficient for Continuation A, whereas it is necessary for Continuation B. Statement 2 is sufficient for A because to say that Jimmy walked through the doorway implies, in the context of this story, that he is now outside the room. Note that the information that Jimmy is now outside the room (Continuation $\mathrm{A}$ ) is highly predictable from Statement 2 , or redundant with it. Continuation $B$ is related by necessity to Narrative Stem 2 because Jimmy must pass through the doorway (it is necessary) before he can slam the door behind himself. However, his passing through the doorway is not sufficient for slamming the door; he could take many other actions. Continuation $\mathrm{C}$ is not causally related to either narrative stem sentence. Although the circumstances precede Continuation $\mathrm{C}$ in the time sequence of events, the circumstances (Narrative Stems 1 and 2) suggest no way in which they are causally necessary or sufficient for Jimmy to adjust his collar.

Aside from necessity and sufficiency, causal continuations may differ in their temporal relation to the stem. They can be consequent to the stem, as in Continuations $\mathrm{A}$ and $\mathrm{B}$ above. Or they can be antecedent to the stem, as in Continuation D. In the latter case, necessity and sufficiency again define the type of causal relation, with Continuation $D$ being both necessary and sufficient for the stem.

The various causal connections among story events collectively form what researchers refer to as a story's causal network (e.g., Trabasso et al., 1984; Trabasso \& Sperry, 1985). The causal network allows one to identify the last event on the causal chain that runs through the story because (1) within the network one can trace a sequence of causal links among story events from the beginning to the end of the story, and (2) research has shown that a reader's flow of attention follows that sequence of links, from antecedents to consequents, as he/she reads the story (Fletcher et al., 1990). Each continuation prompt in Experiment 1 came at the end of the story's unfolding causal chain.

At each continuation point, writers were cued to provide their continuation by the prompt, "What happens next?" Bereiter and Scardamalia's research (1982) suggests that "what next" local planning characterizes much novice story writing, and thus our continuation prompt seems to be a common self-prompt, readily observed in narrative composition.

Despite the experimental control we gain from using narrative stems, and unlike in research on forward inferences, in which readers tend to generate the same inference, we did not expect all writers to generate the same continuation. Rather, we expected writers to creatively generate different ideas that, each in their own way, causally connect to the stem.

\section{Method}

Participants. Thirty undergraduate psychology students at the University of Minnesota participated for extra course credit.

Materials and Procedure. Participants read one short narrative consisting of 37 sentences. Narratives similar to this have been used extensively in text comprehension research. They typically consist of a small number of episodes revolving around the goals of one or a few characters. Participants produced continuations at 16 points in the narrative (see Appendix A). To keep people from reading ahead while they wrote their continuations, the narrative was printed several sentences per page (in a 16-page booklet). The narrative stem sentences were printed at the top of each page followed, near the bottom of the page, by the prompt, "What happened next?" and two blank lines on which participants wrote their continuations. After writing a one-sentence continuation, the participants turned the page, read the next segment of the narrative, wrote another continuation, and so on, proceeding at their own pace. The last sentence of the evolving narrative stem was always in view while people wrote their continuations.

\section{Results}

Two judges used the formal criteria developed by Trabasso and Sperry (1985) to classify each continuation in terms of its causal relation to the last given sentence. For each continuation, judges determined (1) whether it was causally related or not (interrater reliability $=91 \%$ ), (2) whether it was an antecedent to or a consequent of the last stem statement (interrater reliability $=98 \%$ ) and, (3) whether it was causally related to the stem by necessity, sufficiency, or both necessity and sufficiency (interrater reliability $=90 \%$ ).

The leftmost bar in Figure 1 shows the relative occurrence of each type of continuation, across all 16 story prompts and 30 participants ( $N=480$ continuations). The vast majority $(86 \%)$ were causally related to the last stem sentence, and of those, nearly all $(99 \%)$ were consequent to it. Of the causal consequents, nearly all $(98 \%)$ were related at least by necessity. Only a small number $(2 \%)$ of continuations were written in such a way that the 


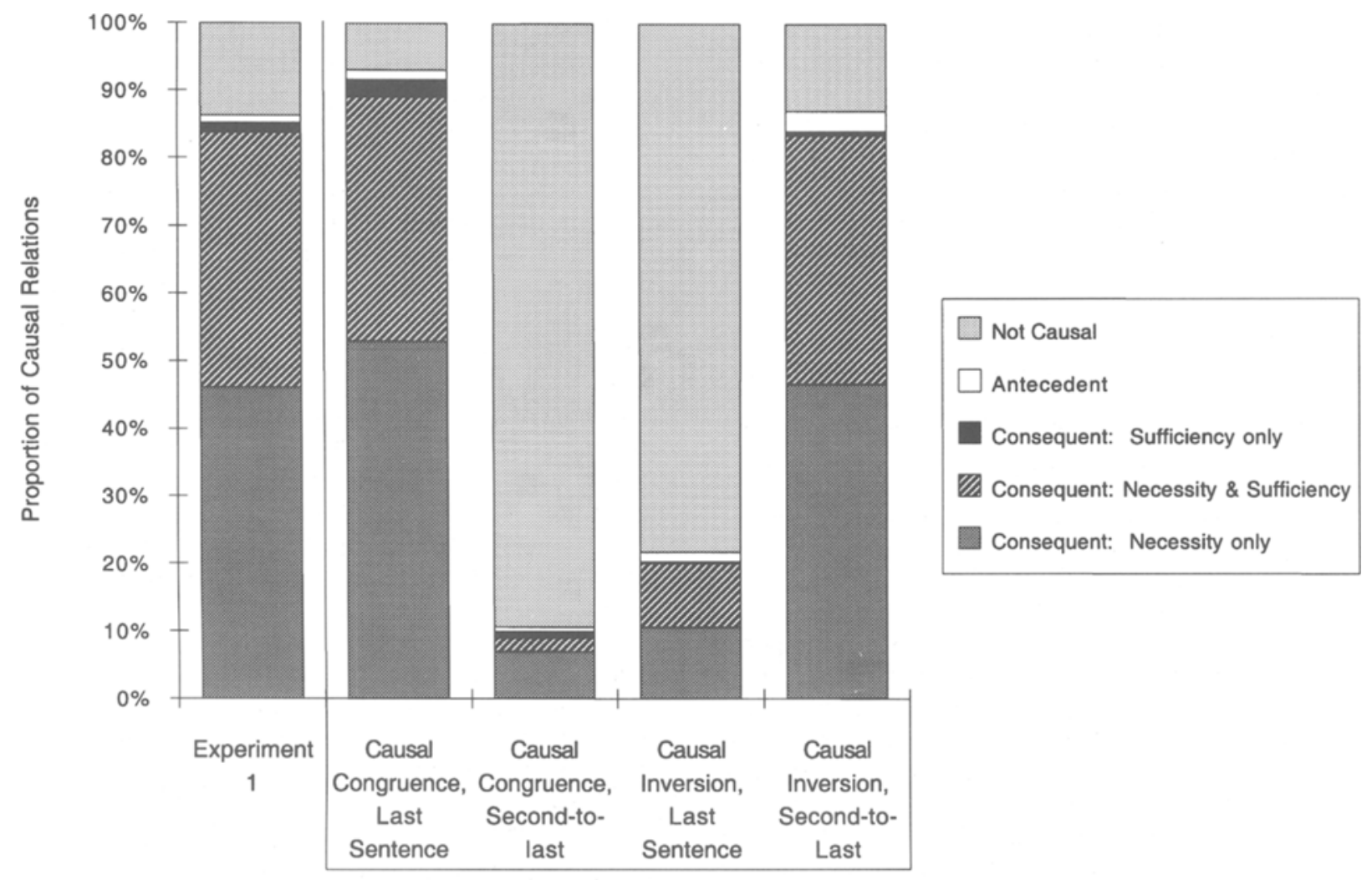

Experiment 2

Figure 1. Relative occurrence of causal relations between continuations and narrative stems in Experiments 1 and 2.

last sentence of the stem was entirely sufficient for the continuation.

Because the data were categorical, chi-square analyses were conducted for the three questions of interest. All results were significant at $p<.001$. First, regarding whether or not continuations were causally related to the last given statement, the results showed that continuations were highly likely to be causally related to the stems $\left[\chi^{2}(1, N=\right.$ $480)=252.3$ ]. Of the 480 continuations, 414 were causally related whereas 66 were not. On the second question, the results showed that when a continuation was causally related to the last given sentence, it was more likely to be a consequent rather than an antecedent $\left[\chi^{2}(1, N=414)=\right.$ 394.24]. Of the 414 causally related continuations, 409 were consequents while 5 were antecedents. Finally, the results showed that when a continuation was a causal consequent to the last given statement, it was more likely to be related through necessity or through both necessity and sufficiency rather than through sufficiency alone $\left[\chi^{2}(2, N=409)=189.91\right]$. Of the 409 causal consequent continuations, 221 were related by necessity only, 181 were related by both necessity and sufficiency, and 7 were related by sufficiency only. We could not test the type of causal relation (necessary, sufficient, necessary and sufficient) of continuations that were antecedent to the last given statement because the expected cell count was too low to satisfy the assumptions of the chi-square test.

\section{Discussion}

The results of Experiment 1 strongly support the hypothesis that causal relations play an important role in the production and connection of ideas in narrative writing. The vast majority of continuations were causally related to the last sentence of the narrative stem. Thus, maintaining a causal connection among events appears to be a strong constraint in the generation and retention of new ideas throughout a narrative. When given the cue "What happened next?" writers tended to continue the action on the causal chain (generate causal consequents) rather than provide information about antecedents to it or than provide purely temporal continuations. Furthermore, writers did not simply write any action that constituted a causal consequent. Rather, they selected ideas that established a relation of causal necessity, either alone or in conjunction with sufficiency, while largely avoiding causal sufficiency alone. We will return to this pattern in the general discussion. Experiment 1 also shows that causality should be regarded as a strong constraint rather than an absolute rule. The fact that $14 \%$ of all continuations were noncausal indicates that writers had choices 
about the kinds of continuations they wrote. Continuations could be and sometimes were noncausal.

Although the multiple continuation prompts of Experiment 1 may accurately resemble a writing session in which the writer must periodically probe memory to produce the next idea sequence, the fact that the narrative in this experiment continues independently of the writer's continuation may encourage him/her to "learn" what kind of continuation we expect - a sort of demand characteristic. Experiment 2 uses the continuation paradigm in a more open-ended way, so that writers could not be influenced by how the researchers continued the narrative stem.

\section{EXPERIMENT 2}

The causal relations among narrative events can be regarded as a chain on which most events are consequences of prior events and are themselves causes of later events. In Experiment 1, the last sentence of each narrative stem described the latest event in the story's evolving causal chain. Thus, being the last event on a causal chain was confounded with being mentioned last in the text order. To disentangle this possible confounding, both text order and causal order were manipulated in Experiment 2. This variation has real-life validity. For reasons of style, variety, or convenience, events in narratives found outside the experimental lab are sometimes presented in inverse causal order by relating a consequent event in the text before its antecedent. Thus, the question of whether it is causal order or text order that determines which ideas serve as a building point for subsequent text is of interest for both methodological and substantive reasons.

One possibility is that writers build onto the last event of the causal chain, even when it does not occur last in the text order. This scenario would be consistent with the finding, obtained in reading comprehension research, that attention flows from one event to its consequent (e.g., Fletcher \& Bloom, 1988; Fletcher et al., 1990). A contrasting possibility is that writers generate ideas based on the last event in the evolving text regardless of its place in a causal network. To test these two possibilities, and to replicate the findings of Experiment 1, we used the continuation paradigm and created two narrative stem conditions: (1) the causal congruence condition, in which the last event of the narrative stem also is the last event on the causal chain (as in Experiment 1), and (2) the causal inversion condition, in which the last event in the narrative stem is second to last on the causal chain, while the last event on the causal chain is the second to last in the text order. See Figure 2 for an example. The causal inversion condition unconfounds text order and causal order. ${ }^{1}$

To gather both converging and diverging evidence, we investigated the type of causal relation, if any, between the writer's continuation and each of the last two sentences of the narrative stem in each condition-yielding four sets of analyses like those of Experiment 1. Following the results of Experiment 1, one would expect that in the causal congruence condition writers would continue action from the causally last (and textually last) sentence of the narrative stem. If causal chain position is important, the continuations should have no causal relation to the second-to-last sentence because it is also second to last in the causal chain. If position on the causal chain is crucial in driving the idea generation, then in the causal inversion condition the continuations should have no causal relation to the last sentence of the narrative stem because it is second to last on the causal chain, but instead should be causally related to the second-to-last sentence because it describes the last event on the causal chain. On the basis of the results in Experiment 1, one would expect the causal relations to consist of causal consequents that are related by necessity or by necessity and sufficiency rather than by sufficiency alone.

\section{Method}

Participants. Sixty University of Minnesota psychology undergraduates participated for extra course credit.

Materials and Procedure. Each participant read and supplied continuations for 10 narrative stems: 5 in the causal congruence condition and 5 in the causal inversion condition. There were 20 different stems in total, averaging 80.65 words $(S D=20.2)$. Each stem appeared equally often in each condition across participants.

At the end of each narrative stem, participants wrote their continuations. Participants were instructed to finish the narrative in five or fewer sentences (see instructions in Appendix B). Thus, in this experiment the instructions did not specifically prompt a continuation for "What happened next?" Each narrative stem was printed on a separate sheet of paper in a booklet. The order of the narrative stems was randomized within blocks of 10 . The 20 narrative stems were not related to each other in theme, character, or plot. Participants provided continuations at their own pace.

\section{Results}

Using the criteria from Experiment 1, judges determined whether or not each continuation was causally related to each of the last two narrative stem sentences (interjudge reliability $=93 \%$ ). If a causal relation was present, judges determined whether the relation was one of necessity, sufficiency, or both necessity and sufficiency (interjudge reliability $=92 \%$ ), including whether it was an antecedent to or consequent of the target critical sentence (interjudge reliability $=98 \%$ ).

The second through fifth bars from the left in Figure 1 show the proportion of each type of continuation in Experiment 2. Results for the causal congruence condition are shown in the second and third bars. The second bar, for textually and causally last sentences, replicates the causal relations of Experiment 1 - continuations were causally related to the last event on the causal chain. The third bar shows that continuations rarely were causally related to events that were neither textually nor causally last. The most important results, those for the causal inversion condition, are shown in the fourth and fifth bars. The fourth bar shows that continuations were not causally related to statements that were textually but not causally last in the stems. In contrast, the rightmost bar shows that 


\section{Beginning of Narrative Stem}

Andy was unhappy in the Civil Engineering program, so he decided to change his major to Geography. He thought he could do better in the Geography program. The Geography department is in the College of Liberal Arts and Civil Engineering is in the Institute of Technology. So his first step was the transfer to CLA.

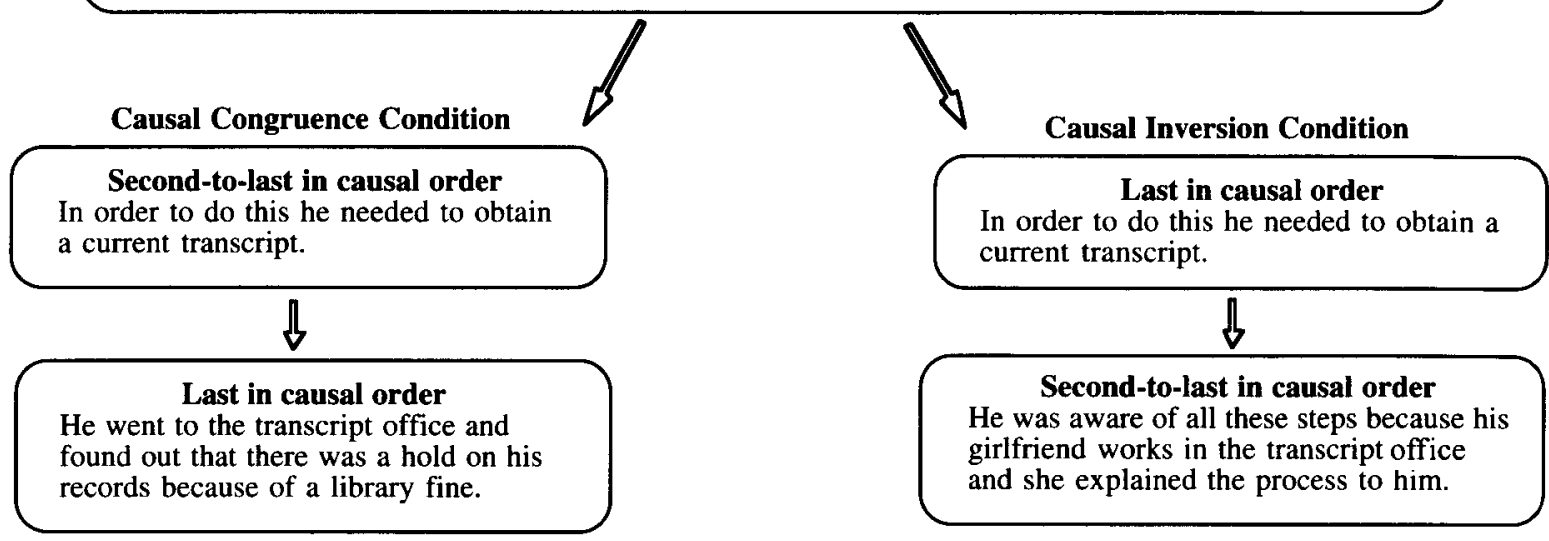

Example Participant Continuations

He found out where to go to
pay the fine and paid it off.

Andy then went to the

transcript office and obtained

the forms he needed.

\section{Examples' Judged Causal Relations to Respective Narrative Stems}

1) Causally unrelated to the second-to-last stem sentence.

2) Related to the last stem sentence by being a necessary and sufficient causal consequent (not an antecedent).
1) Related to the second-to-last stem sentence by being both a necessary and sufficient causal consequent (not an antecedent).

2) Causally unrelated to the last stem sentence.

Figure 2. Example narrative stems, participant continuations, and judged causal relations between continuations and narrative stems for both the causal congruence and causal inversion conditions in Experiment 2.

continuations were causally related to statements that were last in the causal order, even though they were not textually last in the narrative stem.

The statistical analyses of Experiment 2 are divided into four sets-one for each condition-by-sentence group depicted in the second through fifth bars in Figure 1. Each of the four sets of analyses addresses the three questions of interest: (1) Are continuations causally related? (2) Are causal relations antecedent or consequent to prior text? and (3) Given a causal relation, is it one of necessity, sufficiency, or both? Again, the categorical nature of the data required that chi-square analyses be conducted for each question of interest. All reported results are significant at $p<.001$. The first two sets of analyses are for the continuations in the causal congruence condition in terms of their relations to the last and secondto-last given statements, respectively. The third and fourth sets of analyses are for the continuations in the causal inversion condition in terms of their relations to the last and second-to-last given statements, respectively.
The first set of analyses concerned the relations between the continuations and the last sentence of each narrative stem in the causal congruence condition (the second bar in Figure 1). These results confirmed those of Experiment 1 . The majority of continuations were causally related to the last sentence of the stem $\left[\chi^{2}(1, N=300)=\right.$ 221.88 ]. Of the 300 continuations, 279 were causally related to the stem's last sentence whereas 21 were not. Given that a continuation was causally related to the stem's last sentence, it was highly likely to be a causal consequent rather than a causal antecedent $\left[\chi^{2}(1, N=279)=263.22\right]$. Of the 279 continuations, 275 were causal consequents while four were causal antecedents. Of the 275 continuations that were causal consequents to the stem's last sentence, most were related by necessity alone or by both necessity and sufficiency as opposed to sufficiency alone $\left[\chi^{2}(2, N=275)=128.73\right]$. Of the 275 causal consequent continuations, 159 were related by necessity alone, 108 by necessity and sufficiency, and 8 by sufficiency alone. There were too few continuations antecedent to the stem's 
last sentence to statistically test whether or not they differed in type of causal relation (necessity, sufficiency, or both).

The second set of analyses concerned the relations between the continuations and the second-to-last sentence of each narrative stem in the causal congruence condition. Here, writers produced few ideas that were causally connected to these sentences that were neither causally nor textually last. Of the 300 continuations, most (268) were not causally related to the stem's second-to-last sentence $\left[\chi^{2}(1, N=300)=185.65\right]$. For the 32 that were causally related, most were causal consequents to the stem's second-to-last sentence $\left[\chi^{2}(1, N=32)=24.5\right]$. Of the 32 causally related continuations, 30 were causal consequents whereas 2 were causal antecedents. Of the 30 continuations that were causally related as consequents, most were related by necessity alone as opposed to by necessity and sufficiency or by sufficiency alone $\left[\chi^{2}(2\right.$, $N=30)=18.6$ ]. Of the 30 causally related continuations, 21 were related by necessity alone, while 6 were related by necessity and sufficiency and 3 were related by sufficiency alone. As before, there were not enough continuations antecedent to the stem's second-to-last sentence to test statistically.

The third set of analyses concerned the relations between the continuations and the last sentence of each narrative stem in the causal inversion condition. As expected in this condition, writers seldom produced continuations that were causally connected to the textually last sentence if it was not also causally last. The majority of the continuations were not causally related to the stems' last sentences $\left[\chi^{2}(1, N=300)=96.33\right]$. Of the 300 continuations, 235 were not causally related while 65 were. For the 65 that were related, most were causal consequents rather than antecedents of the stem's last sentence $\left[\chi^{2}(1, N=\right.$ $65)=49.98]$. Of the 65 causally related continuations, 61 were consequents while 4 were antecedents. Nearly all 61 consequents were related by necessity or by necessity and sufficiency, rather than by sufficiency alone $\left[\chi^{2}(2\right.$, $N=61)=27.96]$. Of the 61 causal consequent continuations, 32 were related by necessity, 28 by necessity and sufficiency, and 1 was related by sufficiency alone. Again, there were not enough continuations that were antecedent to the stem's last sentence to test statistically.

The fourth set of analyses concerned the relations between the continuations and the second-to-last sentence of each narrative stem in the causal inversion condition. As expected, the majority of continuations were causally related to the causally last sentence even if it was not textually last $\left[\chi^{2}(1, N=300)=164.28\right]$. Of the 300 continuations, 261 were causally related while 39 were not. Of those 261 causally related continuations, most were causal consequents of the stem's second-to-last sentence $\left[\chi^{2}(1\right.$, $N=261)=226.24]$. Of the 261 continuations, 252 were consequents while 9 were antecedents. Of the continuations that were causal consequents, most were related by necessity or necessity and sufficiency rather than sufficiency alone $\left[\chi^{2}(2, N=252)=125.42\right]$. Of the 252 causally consequent continuations, 140 were related by necessity alone, 110 were related by necessity and sufficiency, and 2 were related by sufficiency alone. Again, there were not enough continuations that were antecedent to the stem's second-to-last sentence to test statistically.

\section{Discussion}

As predicted, continuations were most often causally connected to the last event on the story's causal chain, regardless of its position (last or second to last) in the text order of the narrative stem. As in Experiment 1, the causal continuations were overwhelmingly causal consequences, rather than antecedents, of the last event on the causal chains, and causal continuations almost always involved a necessity relation; very few were related by sufficiency alone. We will return to this pattern in the General Discussion.

Writers produced ideas that extended the causal chain despite the following methodological changes from Experiment 1: placing the end of the causal chain second to last in the narrative stem, requiring only a single continuation per narrative stem, using longer narrative stems, providing no specific continuation prompt, and providing no exposure to researcher-generated continuations for the narrative stems.

On occasion, writers did make a causal connection to the stem statement that was not the last event on the causal chain $(10 \%$ in the causal congruence condition and $20 \%$ in the causal inversion condition). Thus, writers can make causal connections to other events, but they do so infrequently. Even in these cases, however, the continuations tended to be consequents rather than antecedents and also reflected primarily necessity relations.

Also, as mentioned in the Results section, a minority of the continuations were causally unrelated to the locally prior narrative stem. Although our focus was on local causal connections, our informal review of the noncausal continuations suggested that they generally were of several types: (1) new actions that referred to a protagonist's global goal (e.g., starting a new episode), (2) obstacles to a protagonist's global goal, (3) elaborations on the stem's last sentence in the causal inversion condition, usually in the form of further motivation for the causally last action, or (4) gratuitous remarks that violated the genre conventions (e.g., producing unrelated and illogical events). Although responses in these categories were not related to the causally last event, the first two (and possibly the third) do relate indirectly to the narrative's global causal structure.

\section{GENERAL DISCUSSION}

These results provide strong support for the hypothesis that causal relations are important in how writers produce and connect new ideas to existing text while writing simple narratives. Writers' continuations were nearly always causal consequences of the narrative stems and were mostly related by necessity or by necessity and suf- 
ficiency rather than by sufficiency alone. Writers maintained a causal relation to the last event on the causal chain regardless of whether this event was textually last or second to last in the narrative stem. Continuations based on the multiple prompts throughout the story in Experiment 1 showed that writers remain sensitive to the causal relations as the story events evolve, not just at particular points in the narrative. Continuations based on the single prompt in Experiment 2 showed that writers are sensitive to causal relations when they are finishing the story, not only when providing a single action. The consistency in results across the experimental manipulations shows that the effect is robust: Causality is clearly one of the constraints writers use to produce and connect new ideas to existing narrative text.

We also observed differences in the relative frequency of the use of necessity and sufficiency in connecting ideas. Most common were relations of necessity alone, followed by relations that reflected both necessity and sufficiency, and, finally, as a distant last, relations that reflected sufficiency alone. This distribution of causal relations may reflect a more general discourse constraint, such as that described by Grice's (1975) maxim of informativeness. In particular, the sizable differences in frequency of the three categories of causal relation may reflect people's sensitivity to the level of information that each relation conveys. The differences in informative value are perhaps best understood by considering the unique contribution to the overall causal network provided by each of the following information sources: the continuation sentence, the last sentence of the narrative stem, the prior narrative stem (all but the last sentence), and the reader's background knowledge. First, consider relations of sufficiency alone. If the last sentence of a stem is sufficient but not necessary for a particular continuation, then the other information in the prior narrative stem contains story events that independently could have resulted in the action described in the continuation (otherwise the last sentence of the narrative stem would also be related by necessity). Thus, a continuation related by sufficiency alone provides no new information to the overall narrative; it is redundant in that it does not provide anything that the reader could not have already inferred from what had been given in the last sentence of the narrative stem or in the prior narrative stem.

Second, consider relations of both necessity and sufficiency. Relative to sufficiency alone, some unique causal information is provided when the continuation is related by both necessity and sufficiency. The presence of both relations does not increase the causal information provided in the continuation sentence, but it does increase the overall causal informativeness for the narrative. That is, by having a sufficiency relation, the continuation is predictable from the last sentence of the narrative stem, but the necessity component informs the reader that there is no other possible cause of the continuation, as is the case when the continuation is related by sufficiency alone. Thus, the unique causal information in this case is that the last sentence of the narrative stem is not redundant with other information already provided in prior text.

Third, consider relations of necessity alone. Continuations related by necessity alone provide the reader with the most unique causal information. The continuation is least predictable from the prior narrative stem when it has no sufficiency relation to it and is thus, from an information theory perspective (e.g., Hamming, 1986; Shannon \& Weaver, 1949), the most informative. In addition, the reader needs to incorporate background knowledge with the last sentence of the narrative stem to achieve causal coherence in the continuation sentence. For example, the last sentence of the narrative stem (last on the causal chain) in one of the stories used in Experiment 2 is, "Her sister had tried to use the oven earlier but discovered that it would not heat up." The continuation, "Kate quickly ran downstairs and brought up an awesome set of tools," is related by necessity alone. Without the information that the stove is broken, Kate's retrieval of tools makes no sense. Yet, when the reader supplies the inference from general knowledge that Kate is going to use the tools to fix the broken stove, the continuation is causally coherent. As a result, necessity-only continuations allow for the greatest change in the mental representation of the text.

Returning to the issue of how writers select ideas to continue an evolving narrative, the overwhelming incidence of necessity relations, alone or in conjunction with sufficiency, is evidence of the combination of two constraints that operate on how ideas are produced and connected to prior narrative text: (1) To provide local coherence, writers produce ideas that are causally related to prior events, and (2) to be informative, writers avoid relations of sufficiency alone when extending the causal chain. When the two constraints are taken together, we observe writers maintaining what could be considered an "intermediate" causal distance among story events. The events are not so weakly related or unrelated as to render the narrative incoherent, nor are the events related so closely by sufficiency that the new events could be easily derived from prior text. Instead, writers compose events at an intermediate causal distance by linking events with necessity relations.

The results indicate that causality is a constraint for writing new ideas in the simple narrative genre-people compose continuations that extend the causal chain. There are at least two ways in which causal relations could act as a constraint. One possibility is that causality limits which ideas are initially generated by serving as a cue. Given that some prior text event is activated, activation might spread in the writer's long-term memory to concepts that are causally related. New story ideas may be generated by a spread-of-activation process that is similar to how forward causal inferences are generated during reading (see, e.g., Kintsch 1998; van den Broek, Young, Tzeng, \& Linderholm, 1999) with causality as the basis for activating new concepts. For example, the writer's general knowledge may include a causal connection between falling down and getting hurt or between betrayal 
and seeking revenge. If the last event on the causal chain is "betrayal," then activation may spread in memory to associated causal consequences, such as "seeking revenge." A second possible way in which causality may constrain writing is by acting as a criterion for choosing among several already-activated candidate ideas. An idea that supplies a causal continuation to prior text may be preferred over others for the causal coherence it provides in the narrative. Our methods did not distinguish between the two possibilities; indeed, both may have been operative in these studies.

Our data provide evidence that in certain conditions, the problem-solving moves that writers make can be predicted. When we know the discourse structure or the rhetorical knowledge on which the writer draws, we also know something about what the writer is likely to do, even when creatively generating new ideas. Although the exact content of creatively generated narrative continuations remains unpredictable, the kind of continuation can be predicted. In this case, the results indicate that continuations tend to be built onto the end of the causal chain and to be related primarily by causal necessity.

How may our results generalize to more complicated narratives, such as longer stories or novels? In the genre of longer narratives there are sure to be other criteria that influence which ideas are produced and retained at certain points in the text. For example, writers sometimes devote considerable text content to descriptions of setting and character. Causality's role in the production of such descriptive idea clusters may be less important or inoperative. However, when writers continue the story action, the role of causal constraints may take on more prominence, with events primarily connected through the relation of necessity rather than sufficiency, so as to avoid stating highly predictable events.

The present results extend our knowledge about the role of causality in how people process narratives in several ways. First, they show that causal relations provide an important constraint on the kinds of ideas that writers produce when adding to narrative text. Although our ability to predict the specific content of continuations is untested, our ability to predict the general kind of continuations that writers produce supports the validity of causal relations as a constraint in composing simple narratives. Second, the finding that writers seldom generate continuations related by sufficiency alone indicates a second kind of discourse constraint-related to Grice's (1975) maxim of informativeness. Not all causal continuations are the same; writers are more informative by continuing the narrative using relations that include necessity. Third, the results show that people are sensitive to causal relations when producing novel, creative ideas, not just when they are asked to recall a narrative or when they are tested for evidence of having made a particular forward or backward inference. This supports the notion that reading and writing processes within a genre rely on some of the same underlying factors, such as a person's sensitivity to causal relations.
Fourth, the results raise important issues for further investigation, such as the whether causal constraints operate during the initial generation or during the eventual selection of the next ideas to be expressed in the evolving text.

The present results also verify the experimental effectiveness of the continuation paradigm and the more general class of hybrid discourse tasks (those that require both reading and writing; Bracewell, Frederiksen, \& Frederiksen, 1982; cf. Flower, 1987; Spivey \& King, 1989). Our twist on the hybrid approach was the degree of experimental control we exercised in the narrative stems and our focus at the local level of idea production for studying writing. In our hybrid task we benefited from using the findings of comprehension research (e.g., that causality structures narrative discourse) to predict the kind of creative content writers produce. This approach has promise to reveal other aspects of discourse processing shared by both reading and writing, thus broadening our perspective on the cognitive processing of language. The continuation paradigm is well suited to investigations of how writers develop new ideas and perhaps select among several or many possible generated ideas. As we structured the continuation paradigm, any planning and revision writers engaged in is likely to be relatively limited in scope. The study of more involved writing processes, such as whole-text planning and revisions of existing text, would require adaptation of the continuation paradigm (e.g., to allow revision of the stem) or the use of different investigative techniques altogether.

In conclusion, whereas there is extensive evidence that causality plays a role in guiding narrative comprehension, there is only limited evidence that causality plays a similar role in narrative writing (e.g., Linzie \& Briggs, 1998). Our research extends that knowledge base. The present results show that causality strongly constrains the kind of narrative ideas writers produce at the local level. The strength of this effect indicates that the production of individual ideas in writing can follow systematic and describable principles (e.g., preserving causal relations). Discovering such principles is necessary for the development of detailed models of cognitive processes. For example, the discovery of a range of systematic principles that operate during comprehension has enabled a series of detailed models of reading processes (e.g., Fletcher \& Bloom, 1988; Gernsbacher, 1990; Graesser \& Clark, 1985; Kintsch, 1988; van den Broek, 1990b). In contrast, models of cognitive processes in writing (e.g., Bereiter \& Scardamalia, 1987; Hayes, 1996; Hayes \& Flower, 1980) have so far described processes at a comparatively more general level. The present findings concerning the role of causal discourse structure in narrative writing contribute toward increasingly detailed models of writing.

\section{REFERENCES}

American Psychological Association (1994). Publication manual of the American Psychological Association (4th ed.). Washington, DC: Author. 
Bereiter, C., \& Scardamalia, M. (1982). From conversation to composition: The role of instruction in a developmental process. In R. Glaser (Ed.), Advances in instructional psychology (Vol. 2, pp. 164). Hillsdale, NJ: Erlbaum.

Bereiter, C., \& SCardamalia, M. (1985). Cognitive coping strategies and the problem of "inert knowledge." In S. F. Chipman, J. W. Segal, \& R. Glaser (Eds.), Thinking and learning skills (Vol. 2, pp. 65-80). Hillsdale, NJ: Erlbaum.

Bereiter, C., \& Scardamalia, M. (1987). The psychology of written composition. Hillsdale, $\mathrm{NJ}$ : Erlbaum.

Bracewell, R. J., Frederiksen, C. H., \& Frederiksen, J. D. (1982) Cognitive processes in composing and comprehending discourse. $E d-$ ucational Psychologist, 17, 146-164.

CoE, R. M. (1987). An apology for form; or who took the form out of the process? College English, 49, 13-28.

Collins, A., \& GenTNER, D. (1980). A framework for a cognitive theory for writing. In L. W. Gregg \& E. R. Steinberg (Eds.), Cognitive processes in writing (pp. 51-72). Hillsdale, NJ: Erlbaum.

Fletcher, C. R., \& Bloom, C. P. (1988). Causal reasoning in the comprehension of simple narrative texts. Journal of Memory \& Language, 27, 235-244.

Fletcher, C. R., Hummel, J. E., \& Marsolek, C. J. (1990). Causality and the allocation of attention during comprehension. Journal of Experimental Psychology: Learning, Memory, \& Cognition, 16, 233-240.

FLOWER, L. (1987). The role of task representation in reading-to-write. In L. Flower, V. Stein, J. Ackerman, M. J. Kantz, K. McCormick, \& W. C. Peck (Eds.), Reading-to-write: Exploring a cognitive and social process (pp. 35-73). New York: Oxford University Press.

GeRNSBACHER, M. A. (1990). Language comprehension as structure building. Hillsdale, NJ: Erlbaum.

Goldman, S. R., \& VarnhageN, C. K. (1986). Memory for embedded and sequential story structures. Journal of Memory \& Language, 25 401-408.

Graesser, A. C. (1981). Prose comprehension beyond the word. New York: Springer-Verlag.

GRAESSER, A. C., \& CLARK, L. F. (1985). The structures and procedure of implicit knowledge. Norwood, NJ: Ablex.

GrICE, H. P. (1975). Logic and conversation. In P. Cole \& J. L. Morgan (Eds.), Syntax and semantics: Vol. 3. Speech acts (pp. 41-58). New York: Academic Press.

HAMMING, R. W. (1986). Coding and information theory (2nd ed.). Englewood Cliffs, NJ: Prentice-Hall.

HarT, M. L. A., \& HonORE, A. M. (1985). Causation in the law. Oxford: Clarendon.

HAYES, J. R. (1996). A new framework for understanding cognition and affect in writing. In C. M. Levy \& S. Ransdell (Eds.), The science of writing: Theories, methods, individual differences, and applications (pp. 1-27). Hillsdale, NJ: Erlbaum

HAYES, J. R., \& Flower, L. S. (1980). Identifying the organization of writing processes. In L. W. Gregg \& E. R. Steinberg (Eds.), Cognitive processes in writing (pp. 3-30). Hillsdale, NJ: Erlbaum.

Hiebert, E. H., Englert, C. S., \& Brennan, S. (1983). Awareness of text structure in recognition and production of expository discourse. Journal of Reading Behavior, 15, 63-79.

Keenan, J. M., Baillet, S. D., \& Brown, P. (1984). The effects of causal cohesion on comprehension and memory. Journal of Verbal Learning \& Verbal Behavior, 23, 115-126.

KeMPER, S. (1982). Filling in the missing links. Journal of Verbal Learning \& Verbal Behavior, 21, 99-107.

KINTSCH, W. (1988). The role of knowledge in discourse comprehension: A construction-integration model. Psychological Review, 95 163-183.

KINTSCH, W. (1998). Comprehension: A paradigm for cognition. Cambridge: Cambridge University Press

KroLL, B. M. (1986). Explaining how to play a game: The development of informative writing skills. Written Communication, 3, 195-218

LiNZIE, B., \& BRIGGS, A. R. (1998, July). Plan implementation in narrative writing. Poster session presented at the annual meeting of the Society for Text and Discourse, Madison, WI.

MACKIE, J. L. (1980). The cement of the universe. Oxford: Clarendon. McCutchen, D. (1986). Domain knowledge and linguistic knowledge in the development of writing ability. Journal of Memory \& Language, 25, 431-444.

McCutchen, D., \& Perfetti, C. A. (1982). Coherence and connectedness in the development of discourse production (Tech. Rep. No. 1982/14). Pittsburgh: University of Pittsburgh, Learning Research and Development Center.

McKoon, G., \& RatclifF, R. (1992). Inferences during reading. Psychological Review, 99, 440-466.

MurRaY, J. D., KuIN, C. M., \& Myers, J. L. (1993). Forward inferences in narrative text. Journal of Memory \& Language, 32, 464-473

Myers, J. L., ShinJo, M., \& DuFFY, S. A. (1987). Degree of causal relatedness and memory. Journal of Memory \& Language, 26, $453-$ 465.

O'Brien, E. J., \& MYERS, J. L. (1987). The role of causal connections in the retrieval of text. Memory \& Cognition, 15, 419-427.

Shannon, C. E., \& WeAver, W. (1949). The mathematical theory of communication. Urbana: University of Illinois Press.

SPIVEY, N. N., \& KiNG, J. R. (1989). Readers as writers composing from sources. Reading Research Quarterly, 24, 7-26.

Torrance, M., Thomas, G. V., \& Robinson, E. J. (1996). Finding something to write about: Strategic and automatic processes in idea generation. In C. M. Levy \& S. Ransdell (Eds.), The science of writing: Theories, methods, individual differences, and applications (pp. 189-205). Hillsdale, NJ: Erlbaum

Trabasso, T., Secco, T., \& van den Broek, P. (1984). Causal cohesion and story coherence. In H. Mandl, N. L. Stein, \& T. Trabasso (Eds.), Learning and comprehension of text (pp. 83-111). Hillsdale, NJ: Erlbaum.

Trabasso, T., \& Sperry, L. L. (1985). Causal relatedness and importance of story events. Journal of Memory \& Language, 24, 595-611.

Trabasso, T., \& van den Broek, P. (1985). Causal thinking and the representation of narrative events. Journal of Memory \& Language, 24, 612-630

VAN DEN BROEK, P. W. (1988). The effects of causal relations and hierarchical position on the importance of story statements. Journal of Memory \& Language, 27, 1-22.

VAN DEN BROEK, P. W. (1990a). Causal inferences in the comprehension of narrative texts. In A. C. Graesser \& G. H. Bower (Eds.), The psychology of learning and motivation (Vol. 25, pp. 175-196). New York: Academic Press.

VAN DEN BROEK, P. W. (1990b). The causal inference maker: Towards a process model of inference generation in text comprehension. In D. A. Balota, G. B. Flores d'Arcais, \& K. Rayner (Eds.), Comprehension processes in reading (pp. 423-446). Hillsdale, NJ: Erlbaum.

van den Broek, P., Risden, K., \& Husebye-Hartmann, E. (1995). The role of readers' standards for coherence in the generation of inferences during reading. In R. F. Lorch \& E. J. O'Brien (Eds.), Sources of coherence in reading (pp. 353-373). Hillsdale, NJ: Erlbaum.

van DEn Broek, P. W., Rohleder, L., \& Narvaez, D. (1996). Causal inferences in the comprehension of literary texts. In R. O. Freedle, R. J. Kreuz, \& M. S. McNealy (Eds.), Advances in discourse processes: Vol. 52. Empirical approaches to literature and aesthetics (pp. 179-200). Norwood, NJ: Ablex.

van den Broek, P., Young, M., Tzeng, Y., \& Linderholm, T. (1999). The landscape model of reading: Inferences and the online construction of memory representations. In H. van Oostendorp \& S. R. Goldman (Eds.), The construction of mental representations during reading (pp. 71-98). Mahwah, NJ: Erlbaum.

VAN DIJK, T. A., \& KINTSCH, W. (1983). Strategies of discourse comprehension. New York: Academic Press.

\section{NOTE}

1. Note that within each condition, responses to the two independent variables (text order and causal order) are connected. For example, when writers choose to build off the last sentence in the text order, they are also choosing a particular level in the causal order. Thus, the proper analysis for these data consists of asking for each of the last two stem sentences whether or not writers established a causal relation, and if so, what the nature of the relation is 


\section{APPENDIX A}

The story from Experiment 1 ("What happened next?" prompt points indicated by asterisks), example continuations, and judged causal relations between continuations and narrative stems.

\section{Story from Experiment 1}

There once was a girl named Sally. One day, Sally's class had show and tell. Sally's best friend, Cathy, showed a picture that she had painted. Cathy told the class how she had made it. Sally was jealous of her friend's project. *1 Sally wanted to do something special for show and tell. *2 Sally got an arts and crafts book from the library. That afternoon, she read the arts and crafts book. ${ }^{*} 3$ The book had pictures of candles. *4 Sally wanted to make a red candle. ${ }^{*}$ Sally found out that candles can be made by melting crayons and pouring them in a cup. She found some crayons and a cup in the kitchen. She put the crayons into the cup. ${ }^{*}$ There were not enough crayons to fill the cup. * Sally wanted to buy some crayons. * Sally took some money from her bank. She walked to the shopping mall. Sally found the arts supply store. She went into the arts supply store. She talked to the sales lady about crayons. The lady showed Sally a lot of boxes. Sally picked out a large box of crayons. She asked the lady how much the box cost. The lady told Sally that the box cost $\$ 2.50$. * Sally bought the box of crayons. ${ }^{*}$ Sally took her new crayons home. Sally melted the new crayons. ${ }^{*}$ Sally held a string in the cup. The wax hardened quickly. Sally had made a beautiful candle. * Sally put her new candle in a holder. She decorated the candle with a ribbon. * The next day Sally carried the candle to school. Sally asked the teacher if she could be in show and tell. The teacher agreed. * Sally won the grandprize blue ribbon for her candle. * Sally was glad the teacher liked her show and tell project. *

\section{Example Continuations and Their Judged Causal Relations}

1. Sally decided she would make her own show and tell picture, one better than Cathy's. (Related by necessity and sufficiency to previous sentence.)

2. Sally asked her parents for ideas and help on her project. (Related by necessity alone to previous sentence.)

3. Sally got materials to make the craft she chose. (Related by sufficiency alone to previous sentence.)

4. Sally decided to build a doll house. (Causally unrelated to previous sentence).

\section{APPENDIX B \\ Instructions for Experiment 2}

Instructions:

In this experiment, we are interested in stories and especially in what makes a story well formed. On each of the following pages you will find the beginning of a very short story (one paragraph long). Your instructions are to first carefully read each beginning. Then, finish the story in five sentences or less, so that it is well formed and one paragraph long. Please write your continuations in the space below each beginning. Work through this booklet one page at a time; don' $t$ look ahead and don' $t$ turn back. If you have any questions at all, please ask the researcher. We appreciate your participation in this study. Thank you.

(Manuscript received February 1, 1999; revision accepted for publication September 2, 1999.) 